\title{
Comparative LCA of different graphene production routes
}

Matteo Cossutta ${ }^{1}$, Jon McKechnie ${ }^{1}$, Stephen J. Pickering ${ }^{2}$

${ }^{1}$ Bioprocess, Environmental and Chemical Technologies Research Group and ${ }^{2}$ Composites Research Group, Faculty of Engineering, University of Nottingham, Nottingham NG7 2RD, UK.

\begin{abstract}
This study is an LCA of three graphene production routes: electrochemical exfoliation of graphite rods, chemical oxidation and subsequent chemical or thermal reduction and chemical vapour deposition (CVD). Different processes for each route are analysed and their cradle-to-gate LCA is presented. A comparative LCA of the least impacting processes for each route is also presented showing that the chemical oxidation process followed by thermal reduction is the least impacting to produce large quantities of graphene when lab equipment is used to its full potential.

A prospective LCA on a likely commercial scale of the least impacting processes is also presented and shows that almost all processes benefit from a scale-up activity and that the least impacting material route remains the chemical oxidation followed by thermal reduction. An optimistic scenario in which all electricity comes from renewable sources is also presented. While this last scenario promotes the more energy intensive processes, the least impacting technology to produce large quantities of graphene remains the chemical oxidation followed by thermal reduction.
\end{abstract}

\section{Introduction}

Graphene is an emerging material with widespread opportunities across the electronics, materials, and energy sectors. Potential applications vary depending on the graphene form. In a monoatomic layer, graphene is transparent, conductive, and flexible, thereby supporting applications such as touchscreen displays [1], photovoltaic cells [2], and membranes [3]. In a bulk, nanoplatelet form, its high surface area, conductivity, and catalytic activity support potential applications increasing energy storage density in supercapacitors [4, 5], improving catalytic efficiency and reducing platinum group metal loading in fuel cell electrodes [6], and improving the lifetime, power output, thermal management and charging time of Li-ion batteries [7-10]. In many applications, graphene can contribute to a range of sustainability objectives by reducing dependency on limited resources, improving energy efficiency, or enabling low-carbon energy technologies. However, as graphene is an emerging material, little is known as to the potential environmental impacts of future manufacturing routes. Consequently, there is limited understanding as to the realisable net benefits of graphene applications.

A diversity of graphene production routes have been investigated in the literature that are capable of producing both monolayer (e.g.: [11, 12]) and bulk graphene forms (e.g.: [13]). Several different processes are being developed in order to produce graphene but the general methods can be grouped into few categories: mechanical exfoliation and cleavage; liquid phase exfoliation; exfoliation by intercalation of molecules; growth on SiC, thermal CVD; growth on metals by precipitation; and chemical synthesis via oxidation and reduction of graphite [14, 15]. Given the wide range of potential production routes at varying stages of development, it is important to improve understanding of their 
environmental impacts. Informing process design at early stage of a technology development will avoid, or at least minimise, the potential impacts at its deployment.

Life cycle assessment (LCA) has an important role in investigating the potential environmental impacts of new technologies to develop understanding of their potential environmental burdens $[16,17]$ considering all activities raw material acquisition through production, use, end-of-life treatment, recycling and final disposal (i.e., cradle-to-grave) [18]. Few LCA studies have investigated nanomaterials; those that have been undertaken typically find production to be substantially more energy-intensive than conventional materials [19-21], although production decisions (e.g., precursor selection; process temperature; etc) can significantly impact life cycle energy consumption and related environmental impacts [22]. While nanomaterial production can be energy-intensive, this can be compensated during the use phase if nanomaterial provides some advantage over conventional materials [21]. For example, Stieberova et al. [23] noted that eliminating the maintenance during the use phase by using self-cleaning coating with nanoparticles outweighs the increase in environmental impacts during the production phase while Pizza et al. [24] found that energy savings during the use of a graphene-reinforced lightweight composite material can result in a net reduction in life cycle energy use.

Prior studies have found the impacts of graphene production to vary significantly between graphene form and production route. To date most of the life cycle studies of graphene production simulated large scale operations using assumptions and hypothetical facilities and equipment $[1,25,26]$, although pilot plant data was utilised in an investigation of planar graphene production [26]. Those studies have considered a number of production routes, using data, in some cases, from patents and papers. In this study, original data from graphene production would, in these cases, improve the reliability of the modelling and provide further insights into how production parameters influence life cycle environmental impacts. The current analysis also expands the number of production routes investigated by previous studies.

In order to develop graphene production routes with minimal environmental impact, it is essential that potential consequences are identified early in the development stage, hence, in this study, we assess the life cycle environmental impacts of three main graphene production routes for the manufacture of both monolayer and bulk graphene products. We also explore the implications of varying key production parameters including reaction media, process inputs and temperatures, and by considering variant production routes. Experimental insights into graphene production parameters are used to inform the development of commercial-scale process models generated by detailed process modelling (using SuperPro Designer [27] software). We consider a range of production parameters for each route to demarcate the potential environmental consequences of graphene manufacture. Results of the study will help to identify sources of significant potential environmental impact, with a goal of informing ongoing development of graphene production processes.

\section{Methodology}

The aim of the study is to evaluate the life cycle environmental impacts of different graphene production methods: 
1. Electrochemical exfoliation of graphite

2. Chemical oxidation of graphite with chemical or thermal reduction

3. Chemical vapour deposition (CVD)

For each production method, we vary a set of graphene production parameters to experimentally evaluate technical implications (e.g., graphene yield) and to analyse the associated life cycle environmental impact. LCA models are developed with GaBi 7 software [28] to quantify impacts on a "cradle-to-gate" basis, including activities from raw materials extraction and processing through to graphene manufacture. We do not consider a specific application for graphene and so use phase and end-of-life activities are excluded from the analysis. The functional unit chosen is the production of 1 gram of graphene, for bulk material, and production of $1 \mathrm{~cm}^{2}$ of graphene for planar material (CVD). The impact categories are those suggested by the ILCD standard methodology [29], specifically: climate change, Ozone depletion, Human toxicity, Respiratory inorganics, lonizing radiation, Photochemical ozone formation, Acidification, Eutrophication, Ecotoxicity, Land use, and Resource depletion. For clarity of presentation, our results discussion focuses on global warming potential (GWP) as normalised results indicate this is the most significant environmental consequence of graphene manufacture (see Supporting Information section S 1.5); results for other impact categories are briefly discussed. Complete LCA results for all 13 impact categories are presented in the Supporting Information (SI). Upstream activities (e.g., electricity generation) are modelled based on the average European average data ( $\mathrm{GaBi}$ database) rather than utilising country-specific information.

Graphene production processes are currently under development, which introduces significant uncertainty to any LCA study. As such, we take a "prospective" approach that accounts for differences in production scale and evolution of background systems over time (e.g., decarbonisation of the energy sector). For each graphene production route, we evaluate three distinct production scenarios: 1) Laboratory scale, using laboratory equipment at maximum capacity/efficiency; 2) Commercial scale, simulating hypothetical industrial production which is informed by experimental insights but utilises standard (generally more energy efficient) equipment and recycling/reuse of process inputs is possible; and 3) Decarbonised electricity, where electricity inputs to the hypothetical commercial scale graphene production are provided primarily from renewable sources to simulate an optimistic future where the energy sector is decarbonised. This scenario is based on the Norwegian electricity mix as a proxy (99.3\% renewable sources (hydroelectric, wind) [30] and associated GWP of $31 \mathrm{gCO}_{2} \mathrm{eq} . / \mathrm{kWh}$ [28]). Limitations with the GaBi databases prevent modelling the decarbonisation of other process inputs (e.g., graphite feedstock; process chemicals), however we consider the potential impacts on results in the Discussion section. Similar prospective analysis approaches to evaluating emerging graphene technologies have been undertaken previously with the goal of evaluating how production scale and background systems influence LCA results [26].

\subsection{Graphene production methods}

\subsubsection{Electrochemical exfoliation of graphite}

Graphene production by electrochemical exfoliation occurs in an electrolytic cell; the electrolysis of water produces hydroxyl and oxygen radicals that initiate the corrosion at the graphite anode on edge sides. This reaction opens the graphite edge planes and allows the electrolyte ions to intercalate between them and to expand the electrode. This weakens the cohesive Van Der Waals forces and leads to a precipitation of electrode material in the form of graphene nanoribbons or graphene sheets 
(from single to multilayer graphene) in the solution [31]. The exfoliated material collected is filtered and the filtrate sonicated to detach further graphene layers from multi-layer graphene.

Exfoliation is evaluated for a set of electrolytes and operating conditions to understand the impact of these parameters on the resulting production rate. Two electrolytes are considered - sodium acetate $\left(\mathrm{CH}_{3} \mathrm{COONa}\right)$ and potassium hydroxide $(\mathrm{KOH})$ - operating at applied potentials of $15 \mathrm{~V}$ and $9 \mathrm{~V}$.

\subsubsection{Chemical oxidation of graphite with chemical or thermal reduction}

Chemical processes for graphene production considered in this study involve two principal stages. Graphite is first oxidised, during which oxygen ions or groups intercalate inside the graphitic structure, expanding it. The oxidised graphite is subsequently reduced, during which the oxygen groups are removed and what remains is a porous structure with randomly organised graphene nanoplatelets often termed reduced graphene oxide ( $\mathrm{rGO}$ ).

Oxidation is achieved by the addition of an oxidative agent to an acid solution containing graphite powder. The process is cooled to control temperature and avoid vigorous reactions from addition of the oxidative agent. We consider a set of graphite oxidation processes which are subsequently referred to as $\mathrm{GO} 1$ to $\mathrm{GO} 5$ :

- GO1 - Modified Hummers method (Fugetsu variant) [32]

- GO2 - Modified Hummers method (Bangal variant) [33]

- GO3 - Modified Hummers method (Jeong variant) [34]

- GO4 - Staundenmaier method [35]

- GO5 - Brodie method [36]

The Modified Hummers variants - Fugetsu, Bangal, Jeong - combine graphite powder with sodium nitrate $\left(\mathrm{NaNO}_{3}\right)$ and sulfuric acid $\left(\mathrm{H}_{2} \mathrm{SO}_{4}\right)$, and utilise potassium permanganate $\left(\mathrm{KMnO}_{4}\right)$ as the oxidative agent, with temperature carefully regulated to achieve the specific process conditions (temperature, time) of each variant. The Bangal variant has the shortest process time $\left(30 \mathrm{~min}\right.$ at $35^{\circ} \mathrm{C}$ ) while the Fugetsu and Jeong variants run for 3 hours at temperatures just below $100{ }^{\circ} \mathrm{C}$. The Jeong variant also uses 10 times more sulphuric acid than the other variants. The Staundenmaier process uses a combination of sulphuric acid and fuming nitric acid $\left(\mathrm{HNO}_{3}\right)$, with potassium chlorate $\left(\mathrm{KClO}_{3}\right)$ as oxidative agent. The reaction runs at ambient temperature for $96 \mathrm{~h}$. The Brodie method uses only fuming nitric acid, with sodium chlorate as oxidative agent $\left(\mathrm{NaClO}_{3}\right)$ and runs at ambient temperature for $24 \mathrm{~h}$.

The reduction of graphene oxide can be achieved by chemical and thermal processes. The chemical reduction consists of mixing $1 \mathrm{~g}$ of graphene oxide (produced by any of the five oxidation processes GO1 to GO5) with ammonia $(1.5 \mathrm{ml})$, hydrazine $(3 \mathrm{ml})$ and $150 \mathrm{ml}$ of deionised water. The mixture is stirred for $24 \mathrm{~h}$ at $85^{\circ} \mathrm{C}$. After cooling the content of the beaker is filtered and washed with $500 \mathrm{ml}$ of deionised water and $50 \mathrm{ml}$ of ethanol [37]. We subsequently refer to chemically reduced graphene as rGOxC, where $x$ refers to the graphite oxidation method ( 1 to 5 ).

The thermal reduction uses a vacuum furnace where the graphene oxide is heated to $700{ }^{\circ} \mathrm{C}$ over approximately $20 \mathrm{~h}$ with a precise heating rate: up to $140{ }^{\circ} \mathrm{C}$ the heating rate is $1.5^{\circ} \mathrm{C}$ per minute and then the sample is kept at $140^{\circ} \mathrm{C}$ for $30 \mathrm{~min}$. The second ramp up is performed with a reduced heating rate of $0.3{ }^{\circ} \mathrm{C}$ per minute up to $350^{\circ} \mathrm{C}$ and then the sample is kept at this temperature for $30 \mathrm{~min}$. In 
the last stage, from $350^{\circ} \mathrm{C}$ to $700^{\circ} \mathrm{C}$, the heating rate is again set at $1.5^{\circ} \mathrm{C}$ per minute and the sample is kept at $700^{\circ} \mathrm{C}$ for $2 \mathrm{~h}$ before turning off the furnace and let the sample cool down. Prior to reduction, the GOx must be dry when starting the thermal annealing and the water evaporation process runs for $24 \mathrm{~h}$ at $55^{\circ} \mathrm{C}$ in a furnace. We employ a similar naming convention for thermal graphene production routes - rGOXT - where $x$ refers to the oxidation method (1 to 5).

\subsubsection{Chemical Vapour Deposition (CVD)}

The mechanism through which CVD works is to let a precursor gas, usually methane or ethane, flow inside a vessel preheated at elevated temperature where it reacts with a catalyst substrate forming graphene on its surface. The temperatures at which the reaction can happen vary from some hundreds degrees to almost the melting point of the substrate [38]. To recover the graphene product, the substrate layer is removed by dissolution. Graphene obtained by CVD is in the form of a single monoatomic layer of carbon and thus is differs from the unorganised nanoplatelets graphene produced by the electrochemical exfoliation and chemical production processes also considered in this study. For consistency with previous studies, we adopt a different functional unit for CVD graphene $\left(1 \mathrm{~cm}^{2}\right)$, also because the area occupied by a gram of planar graphene would exceed $1,000 \mathrm{~m}^{2}$, based on reported graphene measurements [39].

We evaluate two CVD graphene production processes, which follow similar procedures of depositing graphene on a copper sample within a vacuum tube furnace. In the first process, referred to as CVD 1 , the furnace is heated to $960{ }^{\circ} \mathrm{C}$ with an argon/hydrogen gas flow and held for 120 minutes. Hexane is then flowed through the furnace for 5 minutes during which the graphene is deposited. Cooling is achieved under argon/hydrogen flow. The second process (CVD 2) differs only slightly. The furnace is heated to $1035{ }^{\circ} \mathrm{C}$ under a hydrogen flow and held for 120 minutes before a methane/hydrogen mix is flowed through the furnace for $\mathbf{2 0}$ minutes to deposit graphene. The furnace is then cooled with flowing hydrogen. Both these processes are evaluated as batch processes, hence including the warming up of the furnace and not only the moments in which precursor gas is released to form graphene. The subsequent transfer of graphene from the substrate is not considered in this study.

\subsection{Laboratory scale production}

Laboratory scale graphene production is modelled based on experimental insights from graphene production at Fraunhofer IPA (electrochemical exfoliations), Danubia Nanotech (chemical/thermal processes and CVD 1) and Trinity College Dublin (CVD 2) as part of the EU project Electrograph. Measurements of graphene yield, material inputs, and energy consumption are reported directly at the partner facilities. We adjust raw data of laboratory scale production assuming lab equipment is operated at its maximum capacity in order to maximise the throughput and minimise energy consumption at this small scale. No recycling or reuse of reaction media is considered. To conservatively estimate the impacts of waste acid treatment, all acids input to the production processes are assumed to be output as wastes requiring neutralisation. Calcium hydroxide is assumed to be used as a neutralising agent due to its low cost relative to other options.

For electrochemical exfoliation the current is measured at the electrodes and a $90 \%$ efficiency is assumed for the AC-DC power converter. All other quantities are measured using general lab equipment (such as beakers and scales). For all oxidation and reduction processes, data was collected measuring material and energy inputs. Electricity consumption is measured between the mains and the power plug of the furnaces/hot plates measuring power, voltage, current and power factor. 
Electrical energy inputs to the CVD processes (furnace heating) are directly measured in the laboratory. Energy requirements per gram of material are calculated assuming maximised graphene production occurring over a section of the tube furnace where the temperature is uniform (approximately 190 $\mathrm{cm}^{2}$ for CVD 1 and $160 \mathrm{~cm}^{2}$ for CVD 2). Gas flows are taken from experimental methods. The copper substrate is assumed covering the area with uniform temperature and having a thickness of $25 \mu \mathrm{m}$.

\subsection{Commercial scale simulation}

Hypothetical commercial production of graphene is modelled for each of the three production routes. For each route, the lowest impacting process is identified based on experimental results. Experimental insights, including graphene yield, reaction conditions, and material inputs, are used to inform the development of simulation models, which are constructed based on standard processes and equipment. The reaction conditions and graphene yields are assumed to remain the same as at laboratory scale. Assumptions regarding the impacts of increasing production capacity on energy consumption and suitability of material recovery/reuse are specific to each production route and detailed subsequently.

For electrochemical exfoliation, it is not expected that production capacity scale-up will result in significant impacts on process energy consumption. While increasing production would require a larger reaction volume, this could be achieved with similar resistance losses as seen on the experimental scale by maintaining a constant electrode gap and/or stacking individual cells. As such, we assume that electricity requirements will be the same as for the laboratory scale. To account for expected process improvements and optimisation of production parameters, we assume that the commercial-scale process will be capable of achieving the highest yield and energy efficiency results found at the laboratory scale.

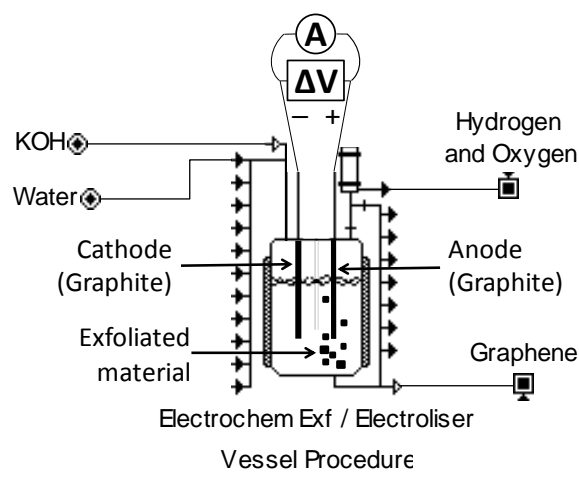

a)

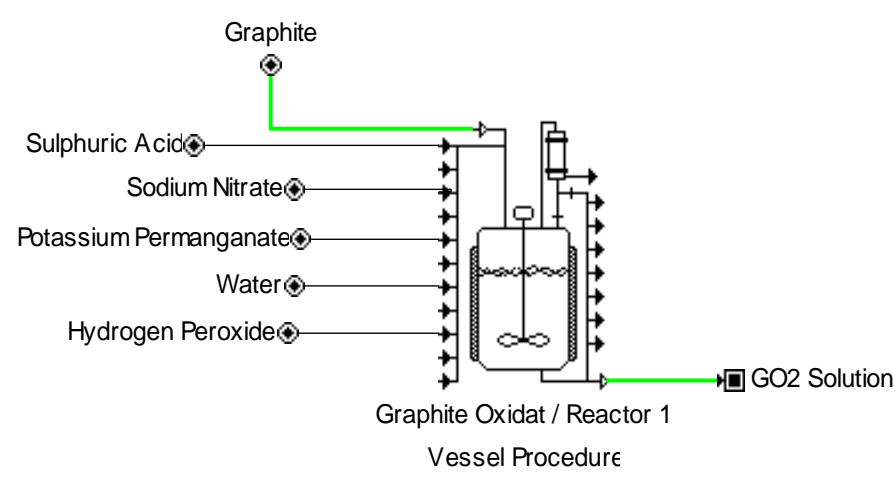

b)

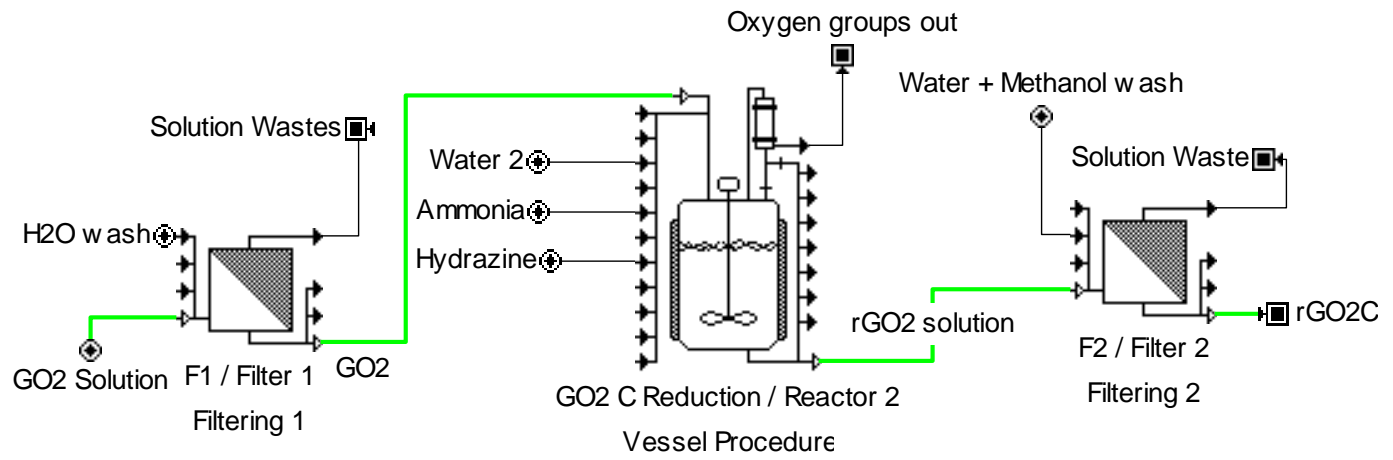

c) 


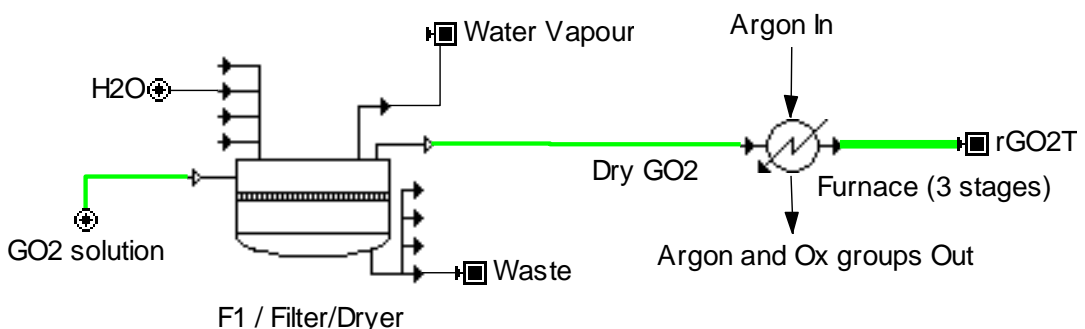

F1 / Filter/Dryer

GO2 Exiccation and Filtration

d)

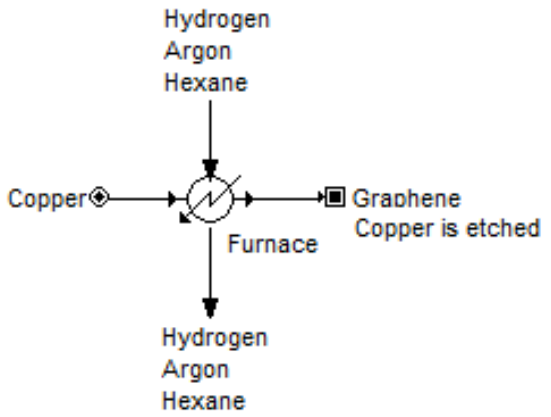

e)

Figure 1: Process simulation flowcharts for the evaluated graphene production routes.

a) Electrochemical exfoliation: current flows in an electrolytic cell at a designated voltage. The ions intercalated into the graphitic rod at the anode exfoliating it and generating graphene flakes.

b) Chemical oxidation: graphite powder and other chemicals (including the oxidising agent) are added in a reaction vessel where they are stirred at constant temperature. The result of this operation is graphene oxide (GO) in a solution of different chemical products.

c) Chemical reduction: $\mathrm{GO}$ is filtered, washed to $\mathrm{pH7}$ and added with other chemicals (including the reducing agent) in vessel at constant temperature in order to obtain reduced graphene oxide ( $\mathrm{rGO}$ ) that is filtered and washed to $\mathrm{pH} 7$.

d) Thermal reduction: $\mathrm{GO}$ is filtered, washed to $\mathrm{pH7}$, dried to remove all water and placed inside a furnace where temperature follows a precise profile in order to reduce the $\mathrm{GO}$ and obtain reduced graphene oxide ( $\mathrm{rGO}$ ).

e) CVD: a copper substrate is placed into a furnace with hydrogen and argon flowing to clean the environment from impurities. At the desired temperature hexane (precursor gas) is released to form a single layer of graphene on the substrate. The substrate is then chemically dissolved.

Process simulation models (Figure 1) are developed in SuperPro Designer v9 [27] to assess the energy balances of the chemical graphene production processes using standard equipment and process conditions as described in section 2.1.2. The chemical oxidation processes (GO1 to GO5) are exothermic and therefore require cooling during oxidant addition to maintain a constant temperature, which is assumed to be provided by chilled water at $5{ }^{\circ} \mathrm{C}$ (e.g., $\mathrm{GO}$ heat of dissolution of $\mathrm{KMnO}_{4}$ in $\mathrm{H}_{2} \mathrm{SO}_{4}$ is $-48 \mathrm{~kJ} / \mathrm{mol}$ and the heat of the oxidative reaction is $-28 \mathrm{~kJ} / \mathrm{mol}$ [40]). After the initial exothermic reaction becomes less vigorous, heat is input to maintain temperature. The thermal and chemical reduction processes also require heat to achieve and maintain process temperatures. All energy inputs (heating, cooling) are assumed to be provided by electricity due to the need to precisely control temperature, assuming a heat transfer efficiency of $90 \%$ and cooling coefficient of performance of 4.5. The reactors are considered adiabatic, as is standard practice for low temperature systems. Energy required for mixing, filtering, and drying activities are assessed based on standard equipment. All process byproducts/wastes are considered disposed of post-production, except for the 
sulphuric acid used in excess for the chemical oxidation. We estimate that at most $5 \%$ of sulphuric acid is consumed in the reactions and therefore estimate that $90 \%$ may be recoverable including process inefficiencies (see SI 2.1 for more details).

For the CVD process commercial-scale production is similarly modelled in SuperPro Designer as a batch process. Energy requirements are estimated assuming adiabatic conditions and $90 \%$ heat transfer efficiency. In practice, graphene production by CVD may employ a continuous process capable of producing a film of graphene by roll-to-roll deposition, thereby avoiding the ramp up energy usage and the argon and hydrogen used to clean the furnace from impurities reducing considerably both the materials and energy requirements of the process but potentially impacting the quality of produced graphene $[41,42]$. We consider how results for such process might vary from that modelled here in the Discussion section.

\section{Results}

\subsection{Laboratory scale analysis}

\subsubsection{Electrochemical exfoliation of graphite}

Across all electrochemical exfoliation production scenarios, which vary electrolyte $(\mathrm{CH} 3 \mathrm{COONa} ; \mathrm{KOH})$ and applied potential $(9 \mathrm{~V} ; 15 \mathrm{~V})$, electricity input is the dominant factor in determining life cycle environmental impact (Figure 2). Energy efficiency is found to increase with higher applied potentials for both electrolytes. At $15 \mathrm{~V}, \mathrm{KOH}$ achieves the highest energy efficiency (1.85 MJ/g graphene). Graphene yield is of secondary importance in terms of life cycle GWP at the laboratory scale. Across the scenarios evaluated, yield ranges from $25 \%$ to $33 \%$, with the highest yield achieved with $\mathrm{KOH}$ electrolyte at $9 \mathrm{~V}$. Overall these results suggest there may be a trade-off in terms of graphene yield and process energy consumption. However, regarding both energy efficiency and graphene yield, we note that there is substantial scope to further optimise the electrochemical exfoliation process by considering more diverse range of operating potentials and electrolytes. Process material inputs notably electrolyte and deionised water for graphene washing/recovery - have a negligible impact, representing combined $1 \%$ of life cycle GWP.

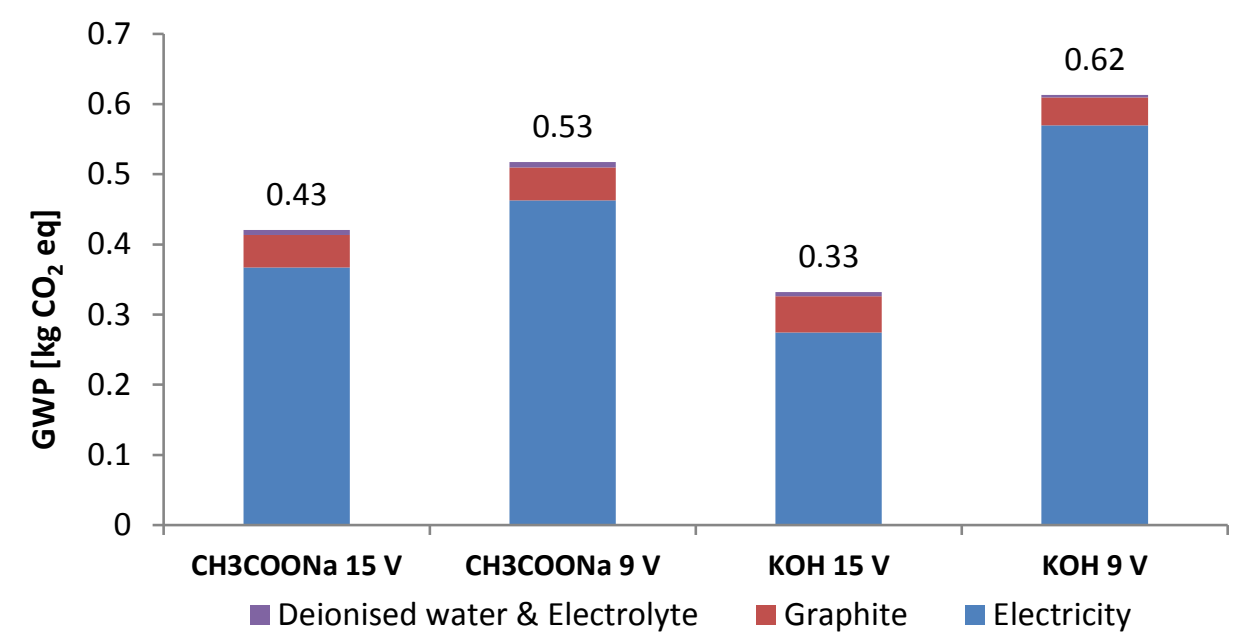

Figure 2 - Life cycle global warming potential of electrochemical exfoliation productions of graphene $(1 \mathrm{~g})$ in laboratory. 
We note similar trends for other environmental impacts, with the notable exceptions of mineral and fossil resource depletion. Resource depletion is most sensitive to graphite consumption and therefore favours production scenarios achieving relatively higher yields (e.g., $\mathrm{KOH} 9 \mathrm{~V}$ ). Other impacts, including water depletion, are dominated by electricity generation (which consumes freshwater in thermal power plant condensers) and therefore direct water inputs to the process have a negligible impact on results. Detailed results for the other environmental impact categories are presented in the Supporting Information (section S 1.1).

\subsubsection{Chemical oxidation processes}

The GWP of graphene oxidation is dominated by chemical inputs and acid neutralisation, with energy consumption a minor contributing factor for most production scenarios. Figure 3 displays the GWP results for graphene oxidation by the five methods considered (GO1 to GO5). The selection of oxidising agent is important, with potassium chlorate (GO4) and sodium chlorate (GO5) resulting in substantially higher GWP than potassium permanganate which is utilised in the Modified Hummers methods (GO1 to GO3). Acid selection and quantity requirements are also significant. The $\mathrm{GO} 4$ and $\mathrm{GO} 5$ scenarios use nitric acid, which is associated with substantially higher GWP than sulphuric acid (GO1 to GO3). Acid production impacts are relatively high for $\mathrm{GO} 3$ as acid input is ten times higher than for $\mathrm{GO} 1$ and GO2. The acid neutralisation causes the GWP impact to almost triple for $\mathrm{GO}$, the process using more acid, roughly double for $\mathrm{GO} 1$ and $\mathrm{GO} 2$ while increases the GWP of GO4 and $\mathrm{GO} 5$ roughly by a $30 \%$. We note, however, that the laboratory-scale results represent a worst-case scenario in which $100 \%$ of the acid is output as waste and requires neutralisation. These results therefore indicate the importance of recovering and reusing acid where feasible in order to reduce environmental impact. Electricity impacts are comparatively minor, but vary significantly between the processes. Electricity is primarily dependent on the temperature and time required for the oxidation process. High temperature requires more heat input and potentially for longer time. For example, the GO4 material (Staudenmaier) is prepared at ambient temperature, but requires mixing over the course of 4 days, while the GO2, (Hummers - Bangal) occurs more rapidly, with reaction time of approximately 2 hours.

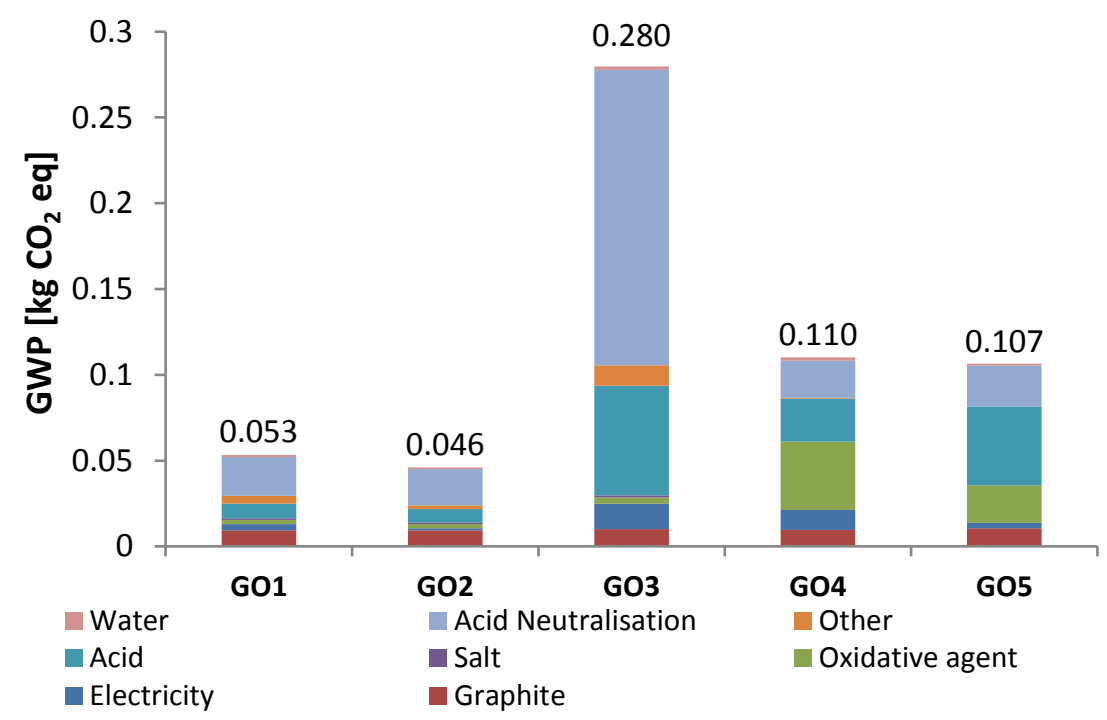

Figure 3. Life cycle global warming potential of graphene oxide production by chemical oxidation $(\mathbf{1} \mathrm{g})$ at laboratory scale. 
Overall, the GO2 route is associated with the smallest GWP due to its relatively low acid input, use of potassium permanganate as oxidising agent, and short process duration which minimises electricity requirements $(10 \mathrm{~kJ} / \mathrm{g})$. As a result, acid neutralisation and graphite consumption are the main contributor to GWP. Similar trends are found for 12 other environmental impact categories which identify GO2 as the lowest impacting production scenario. The only exception is acidification potential, where GO2 performs slightly worse than GO5 due to its reliance on sulphuric acid (rather than nitric acid), which is associated with a relatively larger acidification potential. Further life cycle inventory and impact details for all chemical oxidation scenarios are presented in section S 1.2 of the SI.

\subsubsection{Chemical and thermal reduction processes}

Thermal reduction of graphene oxide results in substantially lower GWP than chemical reduction at laboratory scale (Figure 4). Electricity requirements are similar for both reduction processes: energy required for heating and stirring the reaction mix total $0.38 \mathrm{MJ} / \mathrm{g}$ graphene for chemical reduction; furnace heating required for $\mathrm{GO}$ drying and thermal reduction total $0.28 \mathrm{MJ} / \mathrm{g}$ for the thermal reduction route. However, there are greater opportunities to improve energy efficiency of the chemical reduction process at commercial scale as heat losses from laboratory equipment (hot plate) are very large. Material inputs to the thermal reduction process are minimal (inert gas only), which is associated with small GWP. In contrast, the chemical reduction route consumes mostly hydrazine and ethanol (for cleaning the product), which combined contribute approximately half of total GWP for this reduction process. More details in section S 1.3 of the Supporting Information.

Graphene yields differ between chemical and thermal reduction processes. As GO reduction removes oxygen from the material, a mass loss is inevitable with the process. Experimental data indicates a lower graphene yield associated with thermal reduction relative to chemical reduction (e.g., greater $\mathrm{GO}$ requirements per unit of $\mathrm{rGO}$ produced). It is not clear from the experimental results what drives the differences in yield between the processes as compositional data of the produced material is not available. It may be that thermal reduction is more effective at removing oxygen from the GO material, or alternatively that thermal reduction converts some carbon into $\mathrm{CO}_{2}$.

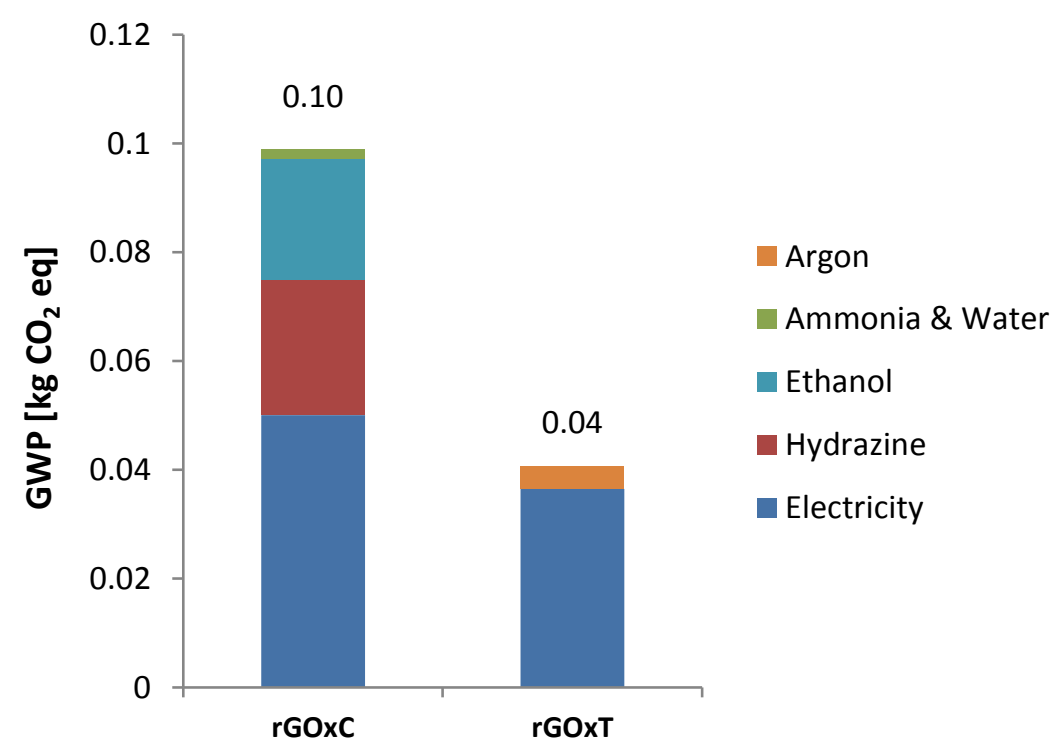

Figure 4. Life cycle global warming potential of graphene oxide reduction $(1 \mathrm{~g})$ by chemical $(\mathrm{rGOxC})$ and thermal ( $\mathrm{rGOxT}$ ) means at laboratory scale. 
Combining results for graphene oxidation (section 3.1.2) and GO reduction completes the cradle-togate analysis. With the lowest impacting chemical oxidation method (GO2) selected, total GWP associated with graphene production is $146 \mathrm{gCO}_{2} \mathrm{eq} . / \mathrm{g}\left(\mathrm{rGO} 2 \mathrm{C}\right.$ - chemical reduction) and $86 \mathrm{gCO}_{2} \mathrm{eq} / \mathrm{g}$ (rGO2T - thermal reduction). Similar results are found for other impact categories with the sole exception of resource depletion: lower graphene yields associated with the thermal reduction process result in higher graphite inputs and, correspondingly, greater non-renewable resource consumption. All other impact categories are primarily driven by electricity consumption and, to a lesser extent, process chemicals consumption, which are both higher for the chemical reduction process.

\subsubsection{Chemical Vapour Deposition (CVD)}

Production of graphene at laboratory scale by CVD cannot be compared with the other routes as the functional unit used is different (for completeness of results, data for comparison using grams as functional unit is available in SI section 1.4). As shown in Figure 5, the GWP associated with CVD-based graphene production is at least 1 order of magnitude smaller than for the other routes, primarily due to the very small quantity produced in comparison. Unlike the bulk graphene synthesis techniques, CVD produces a single layer of graphene used for different types of applications; achieving the functional unit of $1 \mathrm{~g}$ would therefore require deposition over an area of nearly $1,300 \mathrm{~m}^{2}$, hence $1 \mathrm{~cm}^{2}$ is used instead. Given the very different forms of graphene produced, it would not be appropriate to directly compare the energy efficiency or environmental impacts of monolayer graphene with its bulk material counterpart. In fact, the $\mathrm{CO}_{2}$ emitted by producing $1 \mathrm{~g}$ of CVD graphene would be above 115 tons for CVD 1 and above 170 tons for CVD2 (see SI Table S9).

Comparing the two CVD production routes, we find that the CVD 2 process results in approximately $50 \%$ greater GWP than CVD 1, due to its higher operating temperature and lower relative production rate (see life cycle inventory data reported in section S 1.4 of the SI). The results for all other impact categories (Table $8 \mathrm{SI}$ ) depict a similar result showing how CVD 1 has a lower environmental impact due to is lower electricity requirement. The fossil and mineral resources depletion category shows similar results for both processes because of similar use of copper as a substrate for graphene deposition, the main driver for this category.

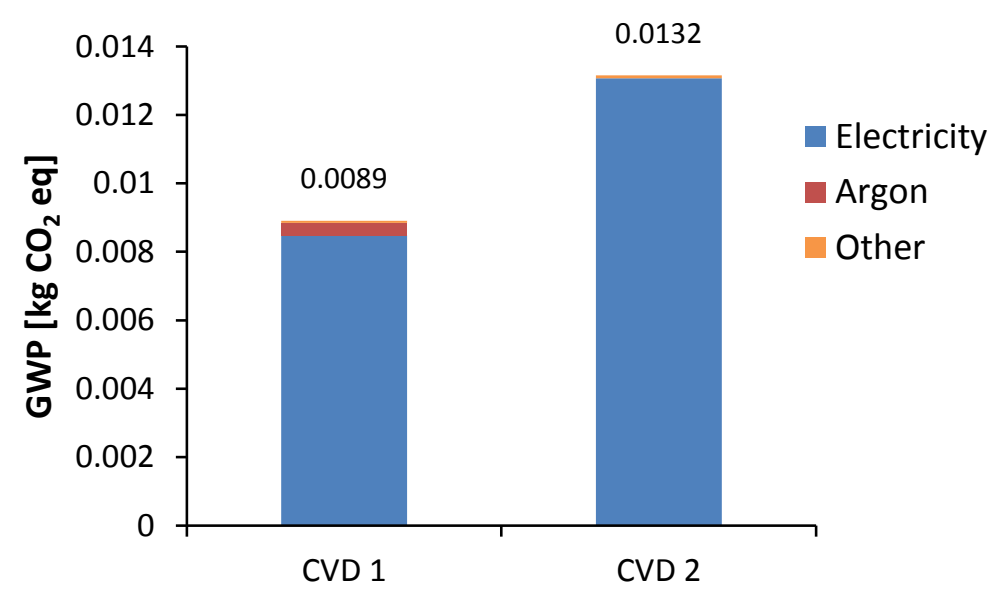

Figure 5. Life cycle global warming potential of laboratory-scale graphene production (1 $\left.\mathrm{cm}^{2}\right)$ by CVD processes. Materials adding up to a less than $1 \%$ are grouped together as "Other". 


\subsection{Commercial scale simulation}

The GWP associated with graphene production at commercial scale by the three production routes (electrochemical exfoliation, chemical oxidation and chemical/thermal reduction, CVD), based on the lowest impacting production scenarios identified by the experimental-scale analysis, is shown in Figure 6 and Figure 7. The simulated commercial-scale production results in lower environmental impact than experimental scale for all production routes considered in this analysis, due to expected improvements in energy efficiency and the ability to recover and reuse process chemicals.

For electrochemical exfoliation, production at commercial scale offers only minor improvements in energy efficiency and associated environmental impacts relative to laboratory scale. This is primarily due to the assumption that electricity consumption (driven by resistance losses) is assumed to not be significantly affected by higher capacity production. Process efficiency could be improved by capturing the co-generated hydrogen and oxygen from the exfoliation reaction; however, further assessment of the viability of this approach is needed. The chemical oxidation process benefits from scale up primarily as heat losses are assumed to be minimised in commercial production resulting in a lower energy use of $6 \mathrm{~kJ} / \mathrm{g}$. As a result, electricity requirements are reduced to $8 \mathrm{~kJ} / \mathrm{g}$ and $10 \mathrm{~kJ} / \mathrm{g}$ for the chemical and thermal reduction routes. The chemical oxidation process further benefits from the recovery and reuse of acid ( $90 \%$ efficiency). The CVD process similarly benefits from more energyefficient production with standard industrial equipment: heat losses are reduced to the minimum, resulting in an energy consumption that is almost 4 orders of magnitude smaller than lab-scale production (64 kJ/ $\mathrm{cm}^{2}$ and $0.02 \mathrm{~kJ} / \mathrm{cm}^{2}$ graphene, respectively).

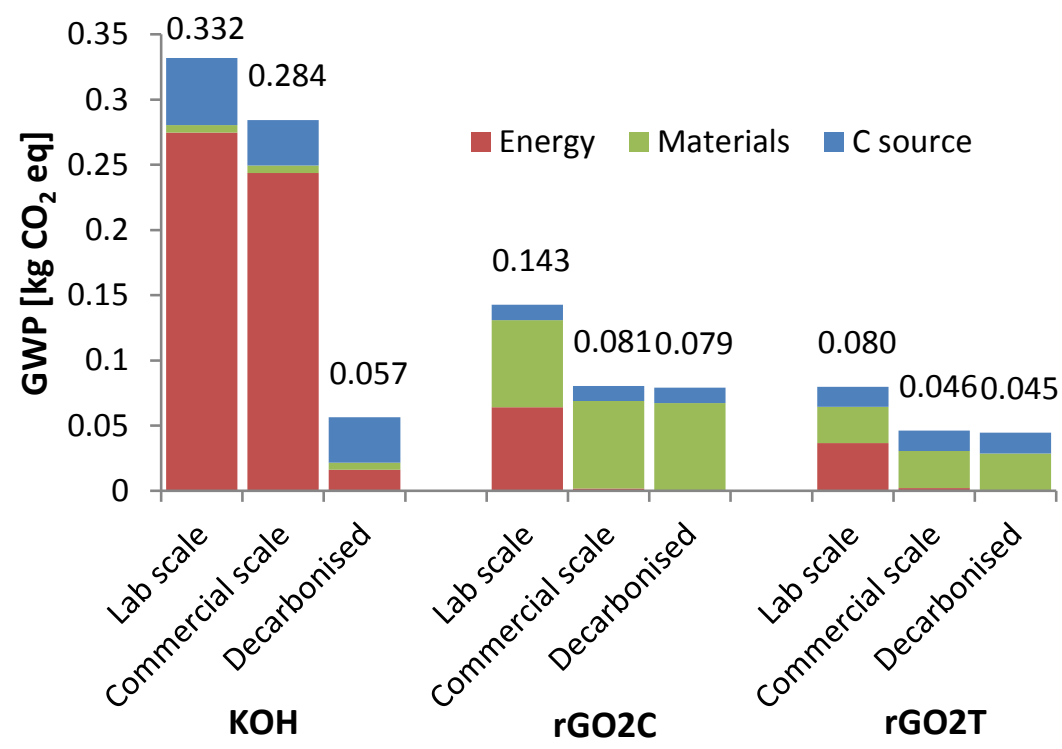

Figure 6. Global warming potential of simulated commercial scale production of graphene $(1 \mathrm{~g})$ by electrochemical exfoliation, chemical oxidation and chemical/thermal reduction

In the decarbonised energy production scenario, environmental impacts of the electrochemical exfoliation and CVD graphene production routes can be substantially reduced. For both production routes, electricity inputs represent the bulk of GWP impact (>80\%) when sourced from the current average EU electricity generation mix. If instead electricity is sourced from renewable energy sources, graphene production GWP can be reduced to $0.057 \mathrm{kgCO}_{2}$ eq./g graphene and $4.39 \mathrm{E}-04 \mathrm{kgCO}{ }_{2} \mathrm{eq} . / \mathrm{g}$ graphene for electrochemical exfoliation and CVD routes, respectively. The GWP associated with the chemical oxidation routes is less sensitive to the electricity source as this represents a smaller share 
of total impact. As a result, we find that electrochemical exfoliation production of graphene can result in similar GWP to the chemical oxidation routes when renewable electricity sources are assumed.

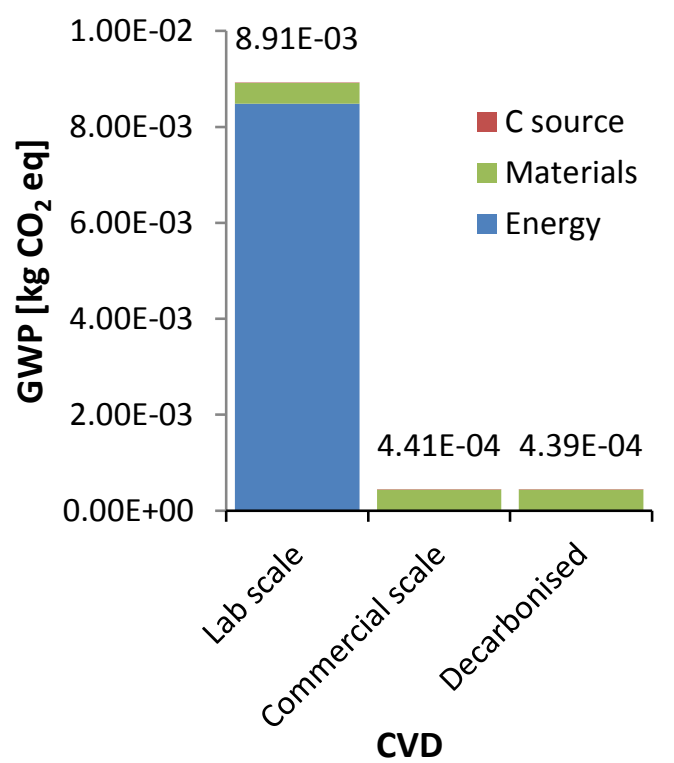

Figure 7. Global warming potential of simulated commercial scale production of graphene $\left(1 \mathrm{~cm}^{2}\right)$ by chemical vapour deposition (CVD).

The electrochemical exfoliation becomes a very interesting solution in the decarbonised scenario that could compete with the chemical processes and this is possible because more than $80 \%$ of the impacts are generated by the electricity use. The thermal route ( $\mathrm{rGO} 2 \mathrm{~T})$ is still the least impacting, but the decarbonisation of the electrical mix is only affecting the electricity used in the foreground system. All the background flows, i.e. the production of all chemicals and gases involved is still performed with the current electricity mix as all those processes are aggregated in $\mathrm{GaBi}$ and it was not possible to modify them accordingly. This leaves a lot of room for improvement for the chemical processes and material for further studies.

Concerning the graphene produced by CVD when produced with more energy-efficient equipment in the commercial scale production simulation, and even more so for the decarbonised electricity scenario, the material inputs to production become the main burden, primarily argon followed by the copper substrate. Argon is used to clean the furnace from impurities, but it is possible that its flow could be minimised by cleaning the furnace during a shorter period prior to the release of the precursor gas (hexane in this case). Similarly, the impacts of etching the copper substrate to release the graphene layer could potentially be avoided using some non-destructive transfer techniques that are under research (i.e.: bubbling transfer on platinum substrate [43]). Graphene production by a continuous CVD process (as in Arvidsson et al. [1]), would avoid transient material and energy inputs to prepare the furnace, thereby reducing the argon and electricity consumption reported here by $97 \%$. With this improvement, the $\mathrm{CO}_{2}$ emissions would reduce to approximately $0.012 \mathrm{gCO}_{2} \mathrm{eq} . / \mathrm{cm}^{2}$ graphene, still several orders of magnitude higher than the bulk graphene production routes (exfoliation, rGOT, rGOC). An overview of all impact categories is presented in section S2 of the SI.

Direct comparison of study results with previous analyses is undertaken based on primary energy demand, which suggests that values are generally comparable with previous analyses. Arvidsson et al. [25] presented a similar Hummers method having energy consumption of $1.1 \mathrm{MJ} / \mathrm{g}$, while the current 
analysis shows a life cycle primary energy demand of $1.64 \mathrm{MJ} / \mathrm{g}$. For the CVD production, direct energy results presented by Arvidsson et al. [1] range from $6.6 \mathrm{~kJ} / \mathrm{cm}^{2}$ to $160 \mathrm{~kJ} / \mathrm{cm}^{2}$ (continuous production with/without methane recovery), while in our study primary energy consumption ranges from 1.7 $\mathrm{kJ} / \mathrm{cm}^{2}$ (continuous, commercial-scale) to $199 \mathrm{~kJ} / \mathrm{cm}^{2}$ (batch, laboratory scale) with different carbon source (hexane). A more detailed comparison is presented in Supporting Information section $\mathrm{S} 3$.

\section{Discussion}

This analysis employs experimental insights to estimate the potential life cycle environmental impacts of a set of graphene production routes at both the laboratory scale and hypothetical commercial scale. We find that impacts vary substantially between the production route, scale, and assumed electricity sources. If compared using mass as functional unit, production of monolayer graphene (by CVD) is found to be approximately five orders of magnitude more impacting than bulk graphene production by electrochemical exfoliation or chemical oxidation routes, which benefit from higher material throughput and greater energy and material efficiency. However, as the CVD process produces planar graphene used in applications that require graphene layers rather than bulk material, its environmental impacts are reported using surface area as functional unit. While all routes are found to benefit from assumed energy and mass efficiencies when manufactured at a hypothetical commercial scale, the chemical reduction processes (with thermal or chemical oxidation) are found to generally be the least impacting methods of manufacturing graphene in large quantities.

The results of this analysis are based on hypothetical production scenarios and are therefore subject to large uncertainty. Reductions shown in environmental impact as production processes are scaled from laboratory to "commercial" scale are driven by key assumptions regarding the achievable energy efficiency, graphene yield, and unconsumed process material recovery for reuse. Despite high uncertainty associated with the analysis, the results are important in identifying the main drivers of environmental impact, linking these to key parameters for each graphene production process and, by extension, highlighting opportunities for ongoing research and process development to mitigate against these impacts. Ongoing refinement of the LCA models to account for process development will be necessary to inform eventual commercial deployment.

The approach undertaken here to evaluate multiple scales of production and trends in background systems (e.g., electricity generation sources) estimates bounds for the potential environmental impacts of future industrial-scale production of graphene with the proposed technologies, in line with Arvidsson et al. [26]. To understand the potential impacts of future graphene production, it is essential to consider how background systems - e.g., the production of energy and material inputs - will change. In this study we are able to assess the potential reductions in graphene production impacts arising from the decarbonisation of electricity generation. We expect that the manufacture of other process inputs could change in the future, given general trends of increasing energy efficiency in process industries [44], the potential for increasing use of renewable resources as feedstocks for fuel and chemical manufacture [45], and benefits from general energy sector decarbonisation. However, data aggregation in LCA datasets prevents us from assessing the consequences of these changes for graphene manufacture.

A further limitation to the LCA method, which is common to other studies of nanomaterials, is the lack of understanding of potential effects of nanomaterials themselves. This limitation holds for all 
nanomaterials as there is very limited information as to the rate of material release at different life cycle stages (production, use, end-of-life), environmental fate upon release, and the ecological and human health impacts of exposure. [19, 46-50]. Further work characterising nanomaterial emissions and associated impacts is essential to better understanding the complete life cycle impacts of nanomaterials, including graphene [17]. Attempts have been made to close the gaps, for example Hischier et al. [51] proposes a way to mitigate those limitations, Deng et al. [52] delivered a characterisation factor for freshwater ecotoxicity for graphene oxide nanomaterials that could be included in future LCAs of graphene, while a closer combination of RA and LCA for nanomaterials is advocated by Grieger et al. [53]. All those suggestions are very valuable for further studies on the topic proposed in this paper. Especially in the light of the potential damages related to the toxicology of graphene [54] that, depending on its size shape, functional group density or charge transfer ability could affect bio-tissue directly at cellular level. For what concerns this study, all electrochemical exfoliations and chemical processes all nanoparticle remain in solution so, no emissions are expected to the work environment and the same can be said about CVD. The thermal reduction, instead, is operated on dried material but in a contained environment, hence no emissions to air are expected. It is essential that future work evaluating graphene applications and fate of materials at product end of life consider the potential environmental impacts of graphene emission.

The promises of graphene applications in a wide range of the technologies are broadly disseminated, but not much is yet known about the environmental implications of its production. The life cycle approach can inform process development with the aim of mitigating environmental risks before this material is deployed. Through ongoing model refinement and interaction with researchers and with industry investigating graphene production routes, this technique can support researchers and decision makers to achieve a desired net benefit for environment and society.

\section{Acknowledgement}

The research leading to these results has received funding from the European Commission's Seventh Framework Programme (FP7/2007-2013) under grant agreement $n^{\circ} 266391$.

\section{Conflicts of interest}

There are no conflicts to declare 


\section{References}

1. Arvidsson, R., et al., Energy and resource use assessment of graphene as a substitute for indium tin oxide in transparent electrodes. Journal of Cleaner Production, 2016. 132(Supplement C): p. 289-297.

2. Zhang, Y., L. Zhang, and C. Zhou, Review of Chemical Vapor Deposition of Graphene and Related Applications. Accounts of Chemical Research, 2013. 46(10): p. 2329-2339.

3. Hegab, H.M. and L. Zou, Graphene oxide-assisted membranes: Fabrication and potential applications in desalination and water purification. Journal of Membrane Science, 2015. 484(0): p. 95-106.

4. Zhao, Y., et al., A Versatile, Ultralight, Nitrogen-Doped Graphene Framework. Angewandte Chemie, 2012. 124(45): p. 11533-11537.

5. Alwarappan, S., et al., Probing the Electrochemical Properties of Graphene Nanosheets for Biosensing Applications. The Journal of Physical Chemistry C, 2009. 113(20): p. 8853-8857.

6. Liu, J., et al., Graphene-based materials for energy applications. MRS bulletin, 2012. 37(12): p. 1265-1272.

7. Qu, Q., et al., Graphene oxides-guided growth of ultrafine Co3O4 nanocrystallites from MOFs as high-performance anode of Li-ion batteries. Carbon, 2015. 92: p. 119-125.

8. Pan, D., et al., Li Storage Properties of Disordered Graphene Nanosheets. Chemistry of Materials, 2009. 21(14): p. 3136-3142.

9. Paek, S.-M., E. Yoo, and I. Honma, Enhanced Cyclic Performance and Lithium Storage Capacity of SnO2/Graphene Nanoporous Electrodes with Three-Dimensionally Delaminated Flexible Structure. Nano Letters, 2009. 9(1): p. 72-75.

10. Brooks, L. and D. Scheffer, Graphene Based Thermal Management Devices. 2015.

11. Somani, P.R., S.P. Somani, and M. Umeno, Planer nano-graphenes from camphor by CVD. Chemical Physics Letters, 2006. 430(1-3): p. 56-59.

12. Dideykin, A., et al., Monolayer graphene from graphite oxide. Diamond and Related Materials, 2011. 20(2): p. 105-108.

13. Nieto, A., D. Lahiri, and A. Agarwal, Synthesis and properties of bulk graphene nanoplatelets consolidated by spark plasma sintering. Carbon, 2012. 50(11): p. 4068-4077.

14. Singh, V., et al., Graphene based materials: Past, present and future. Progress in Materials Science, 2011. 56(8): p. 1178-1271.

15. Bonaccorso, F., et al., Production and processing of graphene and $2 d$ crystals. Materials Today, 2012. 15(12): p. 564-589.

16. Şengül, H. and T.L. Theis, An environmental impact assessment of quantum dot photovoltaics (QDPV) from raw material acquisition through use. Journal of Cleaner Production, 2011. 19(1): p. 21-31.

17. Hischier, R. and T. Walser, Life cycle assessment of engineered nanomaterials: State of the art and strategies to overcome existing gaps. Science of The Total Environment, 2012. 425(0): p. 271-282.

18. ISO, Environmental management - Life cycle assessment - Principles and framework. EN ISO 14040:2006, European Standard.

19. Healy, M.L., L.J. Dahlben, and J.A. Isaacs, Environmental Assessment of Single-Walled Carbon Nanotube Processes. Journal of Industrial Ecology, 2008. 12(3): p. 376-393.

20. Griffiths, O.G., et al., Identifying the largest environmental life cycle impacts during carbon nanotube synthesis via chemical vapour deposition. Journal of Cleaner Production, 2013. 42(0): p. $180-189$. 
21. Miseljic, M. and S.I. Olsen, Life-cycle assessment of engineered nanomaterials: a literature review of assessment status. Journal of Nanoparticle Research, 2014. 16(6): p. 2427.

22. Caramazana-Gonzalez, P., et al., Assessing the life cycle environmental impacts of titania nanoparticle production by continuous flow solvo/hydrothermal syntheses. Green Chemistry, 2017. 19(6): p. 1536-1547.

23. Stieberova, B., et al., Application of ZnO Nanoparticles in a Self-cleaning Coating on a Metal Panel: An Assessment of Environmental Benefits. ACS Sustainable Chemistry \& Engineering, 2017. 5(3): p. 2493-2500.

24. Pizza, A., et al., Life cycle assessment of nanocomposites made of thermally conductive graphite nanoplatelets. The International Journal of Life Cycle Assessment, 2014. 19(6): p. 1226-1237.

25. Arvidsson, R., et al., Prospective Life Cycle Assessment of Graphene Production by Ultrasonication and Chemical Reduction. Environmental Science \& Technology, 2014. 48(8): p. 4529-4536.

26. Arvidsson, R. and S. Molander, Prospective Life Cycle Assessment of Epitaxial Graphene Production at Different Manufacturing Scales and Maturity. Journal of Industrial Ecology, 2017. 21(5): p. 1153-1164.

27. Intelligen Inc. SuperPro Designer. Available from: http://www.intelligen.com/superpro overview.html.

28. Thinkstep. GaBi. Available from: www.gabi-software.com.

29. Joint Research Centre (JRC), ILCD handbook. 2010: Institute for environment and sustainability European Commission Joint Research Centre.

30. IEA Wind. Norway annual report. 2016 [cited 2016 Dec]; Available from: https://www.ieawind.org/annual reports PDF/2015.html.

31. Skákalová, V. and A.B. Kaiser, 4. Graphene Produced by Electrochemical Exfoliation, in Graphene - Properties, Preparation, Characterisation and Devices. 2014, Elsevier. p. 3.

32. Sun, L., H. Yu, and B. Fugetsu, Graphene oxide adsorption enhanced by in situ reduction with sodium hydrosulfite to remove acridine orange from aqueous solution. Journal of Hazardous Materials, 2012. 203-204(0): p. 101-110.

33. Chen, W., L. Yan, and P.R. Bangal, Preparation of graphene by the rapid and mild thermal reduction of graphene oxide induced by microwaves. Carbon, 2010. 48(4): p. 1146-1152.

34. Pham, T.A., et al., One-step reduction of graphene oxide with I-glutathione. Colloids and Surfaces A: Physicochemical and Engineering Aspects, 2011. 384(1-3): p. 543-548.

35. Sheshmani, S. and R. Amini, Preparation and characterization of some graphene based nanocomposite materials. Carbohydrate Polymers, 2013. 95(1): p. 348-359.

36. Kim, H., A.A. Abdala, and C.W. Macosko, Graphene/Polymer Nanocomposites. Macromolecules, 2010. 43(16): p. 6515-6530.

37. Lobato, B., et al., Reduced graphite oxide in supercapacitor electrodes. Journal of Colloid and Interface Science, 2015. 446(0): p. 203-207.

38. Frank, O. and M. Kalbac, 2 - Chemical vapor deposition (CVD) growth of graphene films, in Graphene, V. Skákalová and A.B. Kaiser, Editors. 2014, Woodhead Publishing. p. 27-49.

39. THE ROYAL SWEDISH ACADEMY OF SCIENCES. Scientific Background on the Nobel Prize in Physics 2010 GRAPHENE. Class for Physics of the Royal Swedish Academy of Sciences 2010 10/2014; Available from: http://www.nobelprize.org/nobel prizes/physics/laureates/2010/advanced.html; http://www.nobelprize.org/nobel prizes/physics/laureates/2010/advancedphysicsprize2010.pdf.

40. Lee, S., et al., Large-scale production of high-quality reduced graphene oxide. Chemical Engineering Journal, 2013. 233(0): p. 297-304.

41. Bae, S., et al., Roll-to-roll production of 30-inch graphene films for transparent electrodes. Nat Nano, 2010. 5(8): p. 574-578. 
42. Kobayashi, T., et al., Production of a 100-m-long high-quality graphene transparent conductive film by roll-to-roll chemical vapor deposition and transfer process. Applied Physics Letters, 2013. 102(2): p. 023112.

43. Gao, L., et al., Repeated growth and bubbling transfer of graphene with millimetre-size singlecrystal grains using platinum. Nature Communications, 2012. 3: p. 699.

44. Worrell, E., Productivity benefits of industrial energy efficiency measures. 2011.

45. Vennestrøm, P.N.R., et al., Beyond Petrochemicals: The Renewable Chemicals Industry. Angewandte Chemie International Edition, 2011. 50(45): p. 10502-10509.

46. Sun, T.Y., et al., Dynamic Probabilistic Modeling of Environmental Emissions of Engineered Nanomaterials. Environmental Science \& Technology, 2016. 50(9): p. 4701-4711.

47. Bianco, A., Graphene: Safe or Toxic? The Two Faces of the Medal. Angewandte Chemie International Edition, 2013. 52(19): p. 4986-4997.

48. Bauer, C., et al., Towards a framework for life cycle thinking in the assessment of nanotechnology. Journal of Cleaner Production, 2008. 16(8-9): p. 910-926.

49. Gavankar, S., S. Suh, and A.F. Keller, Life cycle assessment at nanoscale: review and recommendations. The International Journal of Life Cycle Assessment, 2012. 17(3): p. 295-303.

50. Gilbertson, L.M., et al., Coordinating modeling and experimental research of engineered nanomaterials to improve life cycle assessment studies. Environmental Science: Nano, 2015. 2(6): p. 669-682.

51. Hischier, R., B. Salieri, and M. Pini, Most important factors of variability and uncertainty in an LCA study of nanomaterials - Findings from a case study with nano titanium dioxide. Nanolmpact, 2017. 7(Supplement C): p. 17-26.

52. Deng, Y., et al., Deriving characterization factors on freshwater ecotoxicity of graphene oxide nanomaterial for life cycle impact assessment. The International Journal of Life Cycle Assessment, 2017. 22(2): p. 222-236.

53. Grieger, K.D., et al., Analysis of current research addressing complementary use of life-cycle assessment and risk assessment for engineered nanomaterials: have lessons been learned from previous experience with chemicals? Journal of Nanoparticle Research, 2012. 14(7): p. 958.

54. Lalwani, G., et al., Toxicology of graphene-based nanomaterials. Advanced Drug Delivery Reviews, 2016. 105(Part B): p. 109-144. 